Check for updates

Cite this: RSC Adv., 2019, 9, 17897

Received 8th April 2019

Accepted 17th May 2019

DOI: $10.1039 / c 9 r a 02614 b$

rsc.li/rsc-advances

\section{A thio- $\beta$-cyclodextrin functionalized graphene/ gold nanoparticle electrochemical sensor: a study of the size effect of the gold nanoparticles and the determination of tetrabromobisphenol A}

\begin{abstract}
Suxing Luo, ab Yuanhui Wu, (D)*ab Qingsong Mou, ${ }^{\text {ab }}$ Jinhai Lic $^{\mathrm{c}}$ and Xiaoxue Luo ${ }^{\mathrm{d}}$
In this study, a novel tetrabromobisphenol A (TBBPA) sensor was fabricated based on a CTAB-capped gold nanoparticle (AuNPs)-thio- $\beta$-cyclodextrin ( $\mathrm{SH}-\beta-\mathrm{CD}$ )/graphene oxide modified glassy carbon electrode (GCE). The peak current of TBBPA was dramatically enhanced by the AuNPs with a diameter of $6.2 \mathrm{~nm}$ on the modified electrodes compared with the other sized particles (10.1 or $16.1 \mathrm{~nm}$ ). To further improve the electrochemical performance of the modified electrode, the influence of $\mathrm{pH}$ of the buffer solution and the accumulation time on the determination were investigated. The optimum $\mathrm{pH}$ and accumulation time were 7.0 and $180 \mathrm{~s}$, respectively. The developed sensor exhibited good reproducibility, and excellent sensitivity and selectivity, showing a low detection limit $\left(1.2 \times 10^{-9} \mathrm{~mol} \mathrm{~L}^{-1}\right)$ and a linear range from $1.5 \times 10^{-8}$ to $7 \times 10^{-6} \mathrm{~mol} \mathrm{~L}^{-1}$. In addition, a possible oxidization mechanism of TBBPA was also discussed. Finally, this sensor was successfully applied to detect TBBPA in water samples, and the results were consistent with those acquired by high-performance liquid chromatography.
\end{abstract}

\section{Introduction}

Tetrabromobisphenol A (TBBPA) is one of the vastly used brominated flame retardants used in various industrial products, such as building materials, engineering-plastics, printed circuit boards, and so on. ${ }^{1}$ TBBPA is released into the environment if the wastes of these products are abandoned or are inappropriately treated. ${ }^{2}$ To date, its residues have been found in environment media (e.g. soil and water), ${ }^{3,4}$ in wild animals, ${ }^{5,6}$ and even in human beings. ${ }^{7}$ Unfortunately, many reports have demonstrated that TBBPA has toxic effects on the liver, and on the immune and nervous systems in human beings., ${ }^{4,811}$ Therefore, it is of great importance to establish sensitive and simple methods to detect TBBPA. Previously, many methods have been developed to quantify the concentration of TBBPA, including liquid chromatography-mass spectrometry, ${ }^{12}$ high performance liquid chromatography, ${ }^{13}$ electrochemical sensors, ${ }^{2,4,14,15}$ etc. Among these methods, electrochemical sensors, which have the advantages of fast detection, high sensitivity, simple pretreatment, and low cost, have been

\footnotetext{
${ }^{a}$ Department of Chemistry and Chemical Engineering, Zunyi Normal College, Zunyi, 563006, P. R. China. E-mail: yhwull@126.com

${ }^{b}$ Special Key Laboratory of Electrochemistry for Materials of Guizhou Province, Zunyi, 563006, P. R. China

'School of Chemical Engineering, Guizhou University of Engineering Science, Bijie, 551700, P. R. China

${ }^{d}$ Hainan Tropical Ocean University, Sanya, 572022, P. R. China
}

developed to quantify the concentration of TBBPA. Until now, several modified electrodes have been used as electrochemical sensors for the determination of TBBPA, such as CTAB/NG-TPA/GCE, ${ }^{2} \mathrm{MMIP} / \mathrm{CPE},{ }^{16} \mathrm{AB} / \mathrm{GCE},{ }^{17}$ TOMA/GCE,${ }^{18}$ $\mathrm{g}^{2} \mathrm{C}_{3} \mathrm{~N}_{4} / \mathrm{GCE},{ }^{4}$ and SB3-16/ABPE. ${ }^{19}$ Although TBBPA could be oxidized by bare electrodes, low sensitivity is still the main barrier. Meanwhile, the oxidized products of TBBPA can passivate the electrodes. ${ }^{4,20}$ Thus, it is necessary to fabricate a novel electrochemical sensor to solve these problems that has high sensitivity.

Graphene oxide (GO), a single-atom-layer carbon nanosheet, which contains oxygen functional groups (epoxides, alcohols, carboxylic groups) exhibits a negative charge when dispersed in water and has received huge attention in recent years. ${ }^{21,22}$ On the one hand, gold nanoparticles (AuNPs) have good conductivity and superior catalytic activity. On the other hand, AuNPs can easily interact with sulfur to form a S-Au bond, which allows the formation of stable monolayers. ${ }^{23}$ Although AuNPs-GO nanocomposites have been widely reported for electrochemical sensors, ${ }^{24,25}$ the application of a AuNPs-GO nanohybrid in the detection of TBBPA has not previously been attempted. Moreover, the widely used AuNPs (citrate-capped) always carry negative charges due to citrate adsorption on the surface of the particles. ${ }^{26}$ Hence, it is not suitable for citrate-capped AuNPs to be fabricated with GO, owing to the repulsive electrostatic interaction between them. It is well known that $\beta$-cyclodextrin $(\beta-\mathrm{CD})$ is an oligosaccharide composed of seven glucose units, and it has 
a cylindrical-shaped structure with a hydrophobic inner cavity and a hydrophilic exterior. Furthermore, $\beta-\mathrm{CD}$ is environmentally friendly, and is useful in improving the dispersibility of functional materials. ${ }^{27,28}$

In this work, by integrating the advantages of CTABcapped AuNPs, GO and $\mathrm{SH}-\beta-\mathrm{CD}$, a novel electrochemical TBBPA sensor has been developed. First, CTAB-capped gold nanoparticles (AuNPs), which always carry a positive charge due to the cationic surfactant with a positive ammonium head group,$^{29}$ were prepared for the development of a AuNPs/ GO modified electrode due to the electrostatic forces between them. Then, $\mathrm{SH}-\beta-\mathrm{CD}$ was reacted with the AuNPs to form S$\mathrm{Au}$ bonds, and consequently the $\mathrm{SH}-\beta-\mathrm{CD}-\mathrm{AuNPs} / \mathrm{GO} / \mathrm{GCE}$ sensor was fabricated. We also studied the influence of different sized AuNPs on the electrocatalytic behaviors of this sensor. It was found that small sized AuNPs (6.2 nm) were more active compared to the larger ones (10.3 and $16.1 \mathrm{~nm})$. The proposed sensor was sensitive and convenient, due to the synergetic effect of graphene oxide and the AuNPs, together with the excellent accumulation properties of $\beta$-CD. Moreover, this electrochemical method was successfully applied to determine TBBPA in water samples.

\section{Materials and methods}

\subsection{Reagents}

Graphene oxide was purchased from Nanjing Nanotechnology Co., Ltd. SH- $\beta$-CD was purchased from Shandong Zhiyuan Biotechnology Company (China). Chloroauric acid tetrahydrate was purchased from Shanghai Jiuyue Chemical Co., Ltd (China). Sodium citrate was purchased from Shanghai Shenbo Chemical Co., Ltd (Shanghai, China). Hexadecyl trimethyl ammonium bromide (CTAB), L $(+)$ ascorbic acid (L-AA) (>99.0\%), sodium borohydride $\left(\mathrm{NaBH}_{4}\right)$ $(>99.0 \%)$ and tetrabromobisphenol A were purchased from Sinopharm Chemical Reagent Co., Ltd (Shanghai, China). Other chemicals were of analytical grade and were used without further purification. All the solutions used throughout were prepared with ultra-pure water obtained from a Millipore synergy UV system (resistivity, $18.2 \mathrm{M} \Omega \mathrm{cm}$ ). Before use, all glassware and magnetic stirrers were thoroughly soaked in aqua regia and were then rinsed with copious amounts of deionized water.

\subsection{Synthesis and characterization of AuNPs with different particle sizes}

CTAB-capped AuNPs with different particle sizes were synthesized using a seed-mediated method. ${ }^{30}$ Firstly, a $20 \mathrm{~mL}$ solution containing $2.5 \times 10^{-4} \mathrm{~mol} \mathrm{~L}^{-1} \mathrm{HAuCl}_{4} \cdot 4 \mathrm{H}_{2} \mathrm{O}$ and $2.5 \times 10^{-4} \mathrm{~mol} \mathrm{~L}^{-1}$ trisodium citrate was prepared. Then, $0.3 \mathrm{~mL}$ of $0.1 \mathrm{~mol} \mathrm{~L}^{-1}$ icecold $\mathrm{NaBH}_{4}$ was added to the solution while stirring. The solution became orange-red and was used as a seed solution after $1 \mathrm{~h}$ of aging at room temperature $\left(25^{\circ} \mathrm{C}\right)$. Secondly, to prepare the growth solution, a $200 \mathrm{~mL}$ solution containing $2.5 \times 10^{-4} \mathrm{~mol} \mathrm{~L}^{-1}$ $\mathrm{HAuCl}_{4} \cdot 4 \mathrm{H}_{2} \mathrm{O}$ and $0.08 \mathrm{~mol} \mathrm{~L}^{-1} \mathrm{CTAB}$ was obtained, and the solution was heated until it became a clear orange color. For set $\mathrm{A}$
(AuNPs-1), $0.05 \mathrm{~mL}$ of the $0.10 \mathrm{~mol} \mathrm{\textrm {L } ^ { - 1 }}$ freshly prepared L-AA solution was gently mixed with $7.5 \mathrm{~mL}$ of the growth solution. Subsequently, $5 \mathrm{~mL}$ of the seed solution was added while stirring until the solution turned red. By the same method the AuNPs in sets B (AuNPs-2) and C (AuNPs-3) were prepared. $9 \mathrm{~mL}$ of the growth solution was then mixed with $0.05 \mathrm{~mL}$ of $0.1 \mathrm{~mol} \mathrm{~L}^{-1}$ ascorbic acid solution, and a $1.0 \mathrm{~mL}$ solution from set A or set $\mathrm{B}$ was added while stirring for $10 \mathrm{~min}$. Finally, the as-prepared samples were centrifuged and were re-dispersed three times to remove excess CTAB. The morphology and the particle size of the CTAB-capped AuNPs were characterized using a transmission electron microscope (TEM, Tecnai G2 F20 S-Twin, FEI, USA) and dynamic light scattering (DLS).

\subsection{Electrochemical sensor (SH- $\beta$-CD-AuNPs/GO/GCE) fabrication}

The fabrication process of the $\mathrm{SH}-\beta$-CD-AuNPs/GO/GCE sensor and sensing of TBBPA by the electrochemical method are shown in Scheme 1. Prior to use, a glassy carbon electrode (GCE, $\varnothing=3 \mathrm{~mm}$ ) was polished successively with a 0.3 and $0.05 \mu \mathrm{m}$ alumina slurry, rinsed with water, ultrasonicated in $\mathrm{HNO}_{3}(1: 1)$, sodium hydroxide (0.1 M) and absolute alcohol in turn for three minutes, washed in water for $3 \mathrm{~min}$ and finally dried in air. Firstly, $5 \mu \mathrm{L}$ of a $0.5 \mathrm{mg}$ $\mathrm{mL}^{-1}$ GO aqueous dispersion was carefully cast on the surface of the well-polished GCE and dried in air. Then, the electrode was immersed into the positively charged CTAB capped-AuNPs for $1 \mathrm{~h}$ and was then rinsed with water. The AuNPs/GO modified electrode was formed due to the interaction of electrostatic forces between the positively charged AuNPs and the negatively charged GO nanoparticles. Finally, the AuNPs/GO modified electrode was soaked in an aqueous solution of $\mathrm{SH}-\beta$-CD $\left(4 \mathrm{mg} \mathrm{mL}{ }^{-1}\right)$ in a water bath $\left(50{ }^{\circ} \mathrm{C}\right)$ for $4 \mathrm{~h}$ for the $\beta$-CD-SH-AuNPs/GO/GCE sensor preparation.

Electrochemical experiments were carried out on a 2273 electrochemical system (Princeton Applied Research PARSTAT 2273 Electrochemical Workstation). A three-electrode system was used in the experiment with modified GCE (3 $\mathrm{mm}$ diameter) as the working electrode, and a saturated calomel electrode (SCE, and all the other potentials hereafter were relative to this) and a platinum $(\mathrm{Pt})$ wire electrode were used as the reference and counter electrodes, respectively. All experiments were performed at room temperature.

\subsection{Preparation of the water samples}

Water samples were obtained from the Guizhou Chishui river basin (Guizhou, China). Firstly, the water samples were filtered with $0.22 \mu \mathrm{m}$ membranes. Next, the filtered water samples were mixed with PBS buffer and the $\mathrm{pH}$ value was adjusted to 7.0. Differential pulse voltammetric studies were carried out and the concentrations of TBBPA in the water samples were determined. For the HPLC method, the water samples were mixed with methanol $(1: 1, \mathrm{v} / \mathrm{v})$. The TBBPA concentrations were determined by a liquid chromatography machine equipped with a standard micro auto sampler (HPLC, Agilent 1200, Agilent, USA). 


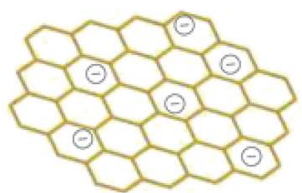

GO

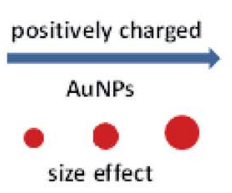

size effect
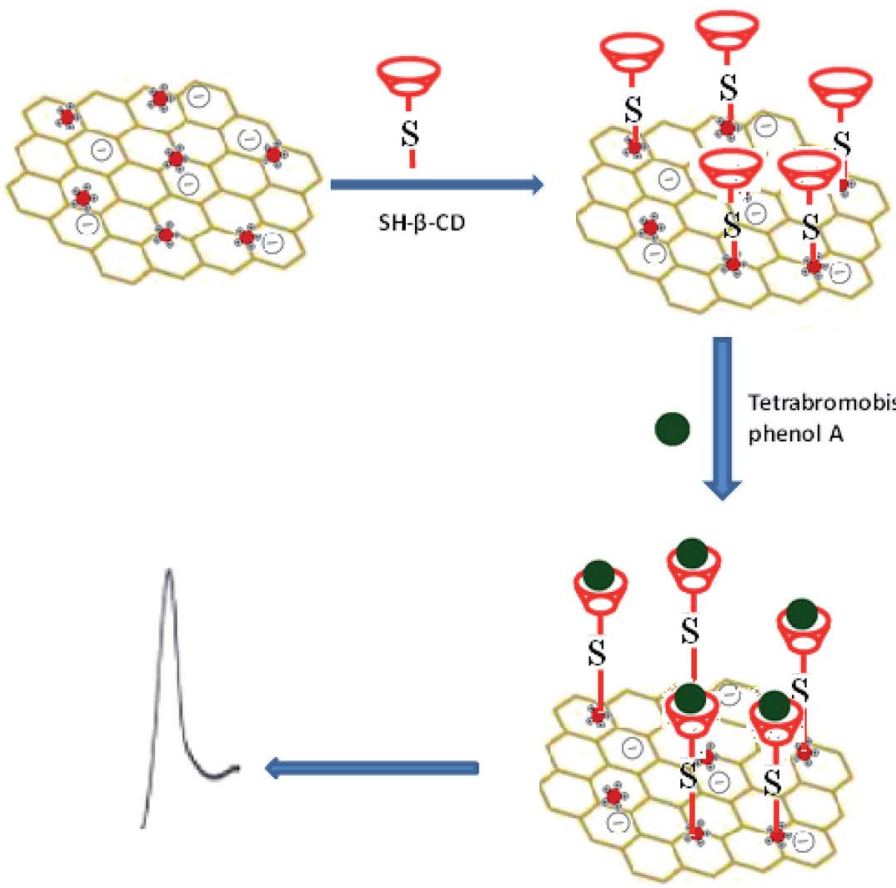

Scheme 1 Illustration of the procedure for the preparation of SH- $\beta-C D-A u N P s / G O / G C E$ and the sensing of TBBPA by an electrochemical strategy.

\section{Results and discussion}

\subsection{Characterization of AuNPs with different particle sizes}

The TEM images and DLS results for the different sizes of AuNPs are shown in Fig. 1 and 2, respectively. As shown in
Fig. 1, most of the AuNPs are ellipsoidal or spherical with an average size of 6.2, 10.3 and $16.1 \mathrm{~nm}$ for AuNPs-1, AuNPs-2, and AuNPs-3, respectively. Furthermore, the size distributions of the AuNPs were investigated with dynamic light scattering (DLS). As displayed in Fig. 2, the mean size for the
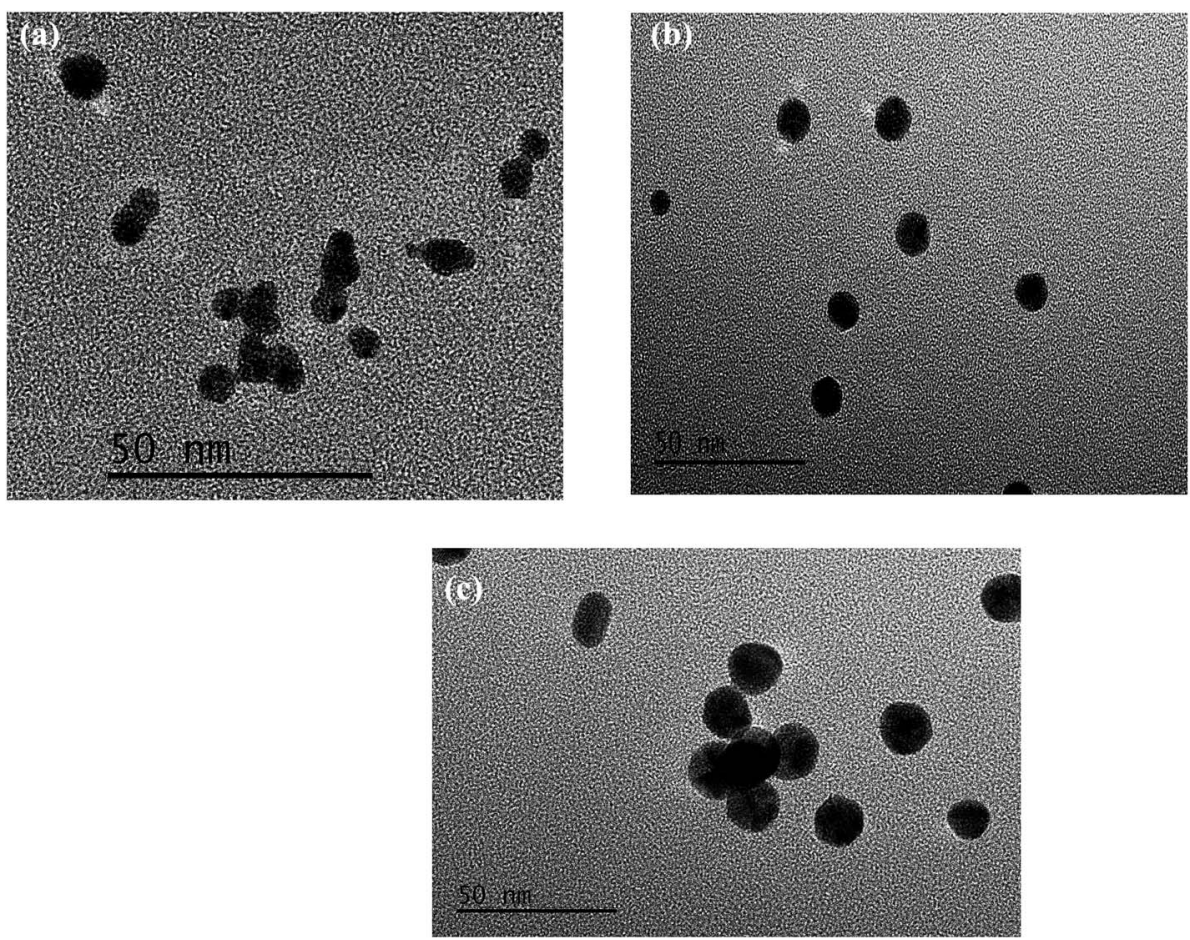

Fig. 1 TEM micrographs of the different sized AuNPs: (a) AuNPs-1; (b) AuNPs-2; (c) AuNPs-3. 


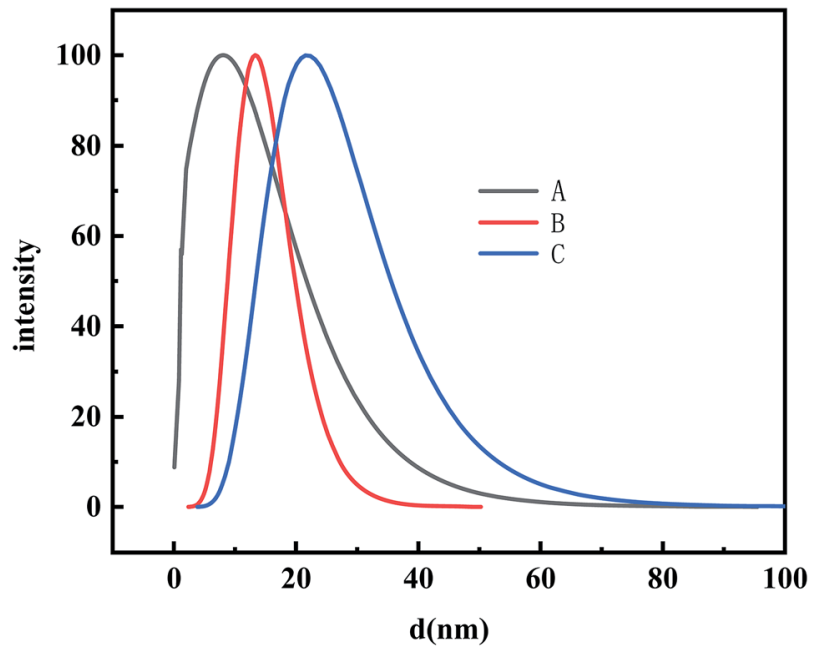

Fig. 2 DLS curves of the different sized AuNPs: (A) AuNPs-1; (B) AuNPs-2; (C) AuNPs-3.

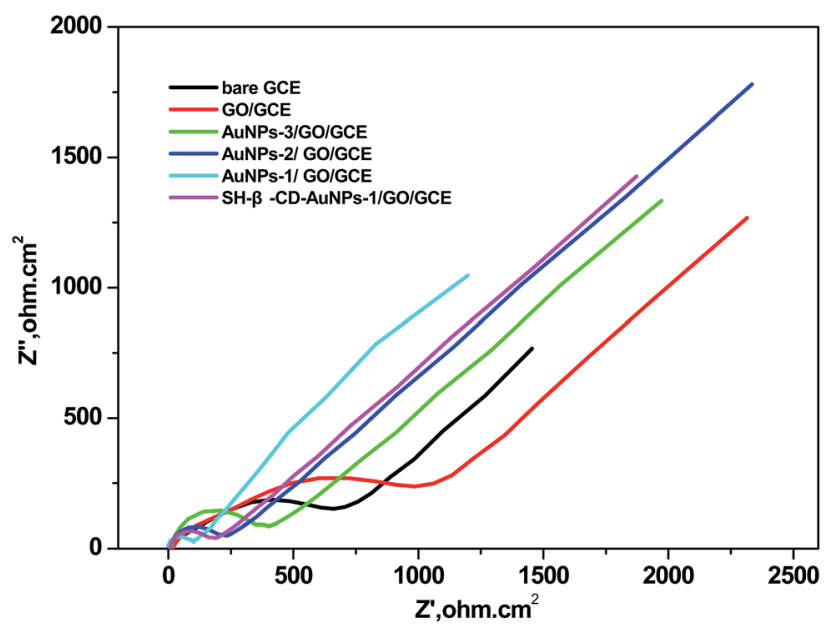

Fig. 3 Electrochemical impedance spectroscopy results of the different modified electrodes in $5 \times 10^{-6} \mathrm{~mol} \mathrm{~L}^{-1} \mathrm{Fe}(\mathrm{CN})_{6}{ }^{3-/ 4-}$ containing $0.1 \mathrm{M} \mathrm{KCl}$ solution $(\mathrm{pH}=7.0)$.

AuNPs in sets A, B and C was 7.8, 11.8 and $18.2 \mathrm{~nm}$, respectively. The results of the DLS curves were consistent with the TEM images.

\subsection{Influence of the size of the AuNPs}

Electrochemical impedance spectroscopy (EIS) and cyclic voltammetry $(\mathrm{CV})$ were applied to investigate the influence of the particle size of the AuNPs. The results of differently modified electrodes (bare GCE, GO/GCE, AuNPs-1/GO/GCE, AuNPs-2/GO/ GCE, AuNPs-3/GO/GCE, and SH- $\beta$-CD-AuNPs-1/GO/GCE) in 5.0 $\times 10^{-6} \mathrm{~mol} \mathrm{~L}^{-1}\left[\mathrm{Fe}(\mathrm{CN})_{6}\right]^{3-/ 4-}$ aqueous solution containing $0.1 \mathrm{~mol} \mathrm{~L}^{-1} \mathrm{KCl}$ are shown in Fig. 3. For the bare GCE, a semicircle can be seen in the high-frequency region, indicating large electron transfer resistance. Compared with the bare GCE, the semicircle of GO increased dramatically, suggesting that the GO film had the larger obstruction effect and made charge transfer

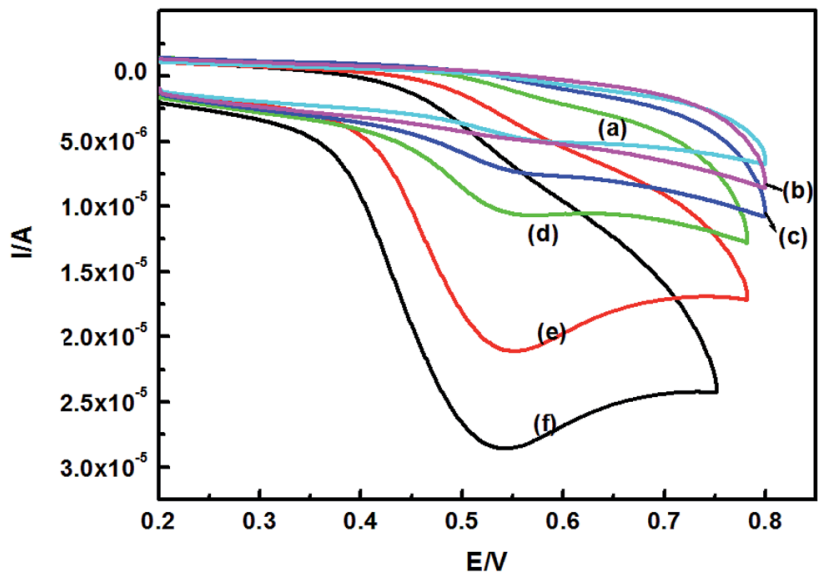

Fig. 4 Cyclic voltammograms of (a) bare GC, (b) GO/GCE, (c) AuNPs1/GO/GCE, (d) SH- $\beta$-CD-AuNPs-3/GO/GCE, (e) SH- $\beta$-CD-AuNPs-2/ $\mathrm{GO} / \mathrm{GCE}$, and (f) $\mathrm{SH}-\beta-\mathrm{CD}-\mathrm{AuNPs}-1 / \mathrm{GO} / \mathrm{GCE}$ in $5 \times 10^{-7} \mathrm{~mol} \mathrm{~L}^{-1}$ TBBPA and PBS buffer solution $(\mathrm{pH}=7.0)$.

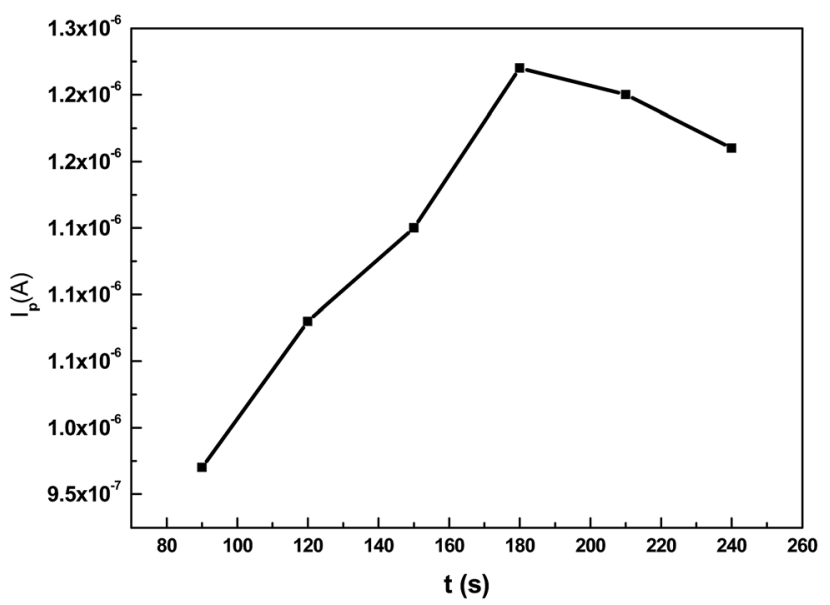

Fig. 5 The effect of accumulation time on oxidation peak current.

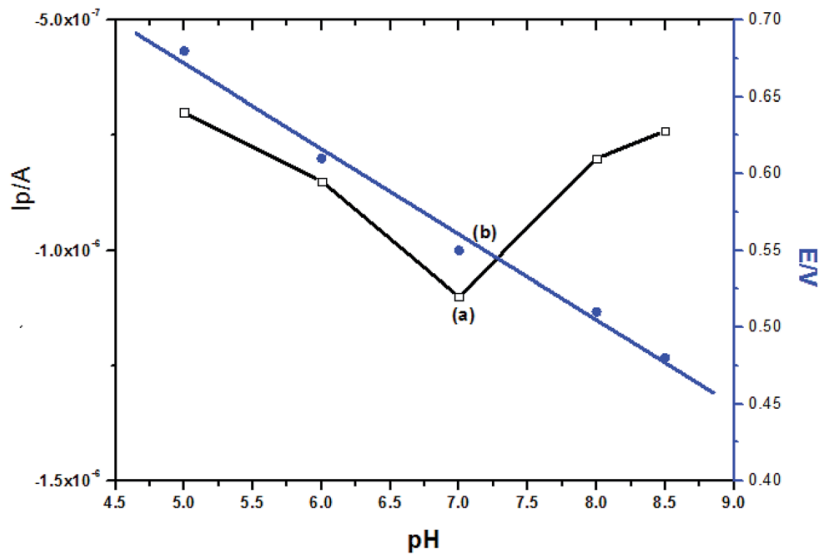

Fig. 6 The effects of $\mathrm{pH}$ on (a) the peak current and (b) the potential.

difficult. This could be attributed to GO exhibiting negative charge with a zeta-potential value of $-47 \mathrm{mV}$. Moreover, owing to the CTAB-capped AuNPs carrying positive charges, the 


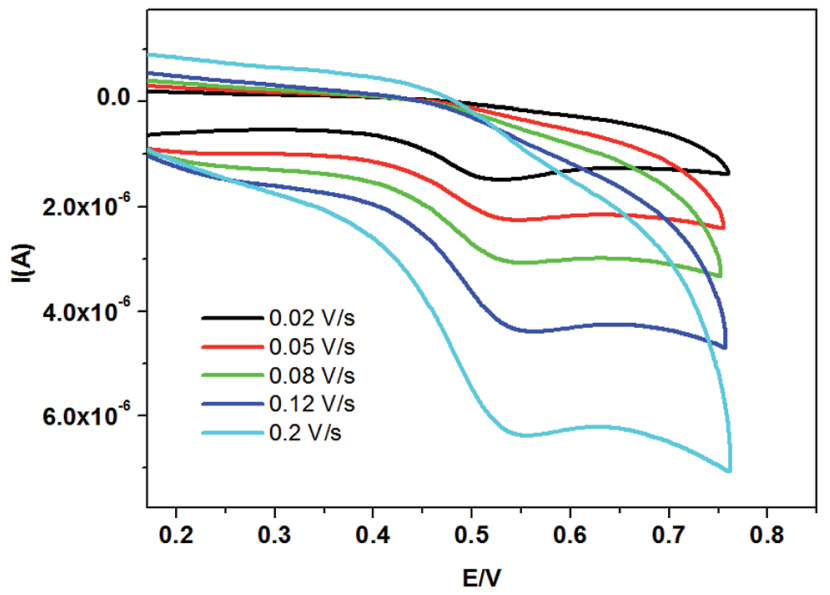

Fig. 7 Cyclic voltammograms of $\mathrm{SH}-\beta-\mathrm{CD}-$ AuNPs-1/GO/GCE in 0.1 $\mu \mathrm{M}$ TBBPA at different scan rates.

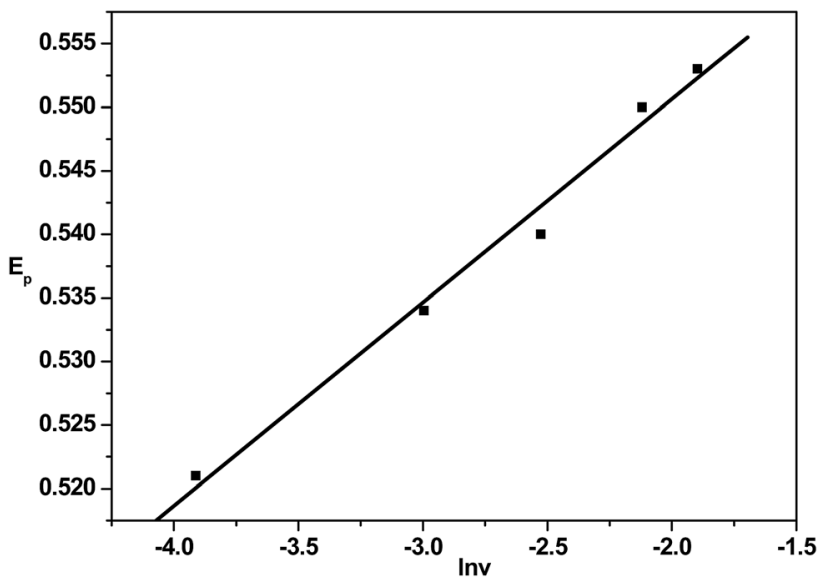

Fig. 8 The relationship between the peak potential and the natural logarithm of the scan rate.

resistance decreased dramatically after different sizes of the AuNPs were modified onto the GO/GCE, indicating a smaller resistance to interfacial electron transfer. The resistance was smallest when the size of the AuNPs was $6.2 \mathrm{~nm}$, implying that the $6.2 \mathrm{~nm}$ AuNPs had the best conductivity and obviously promoted electron transfer. After assembling $\mathrm{SH}-\beta-\mathrm{CD}$ on AuNPs-1/GO/GCE, the resistance of the electrode increased, indicating that $\mathrm{SH}-\beta-\mathrm{CD}$ has poor conductivity. These results confirmed that SH- $\beta$-CD-AuNPs/GO/GCE was successfully fabricated.

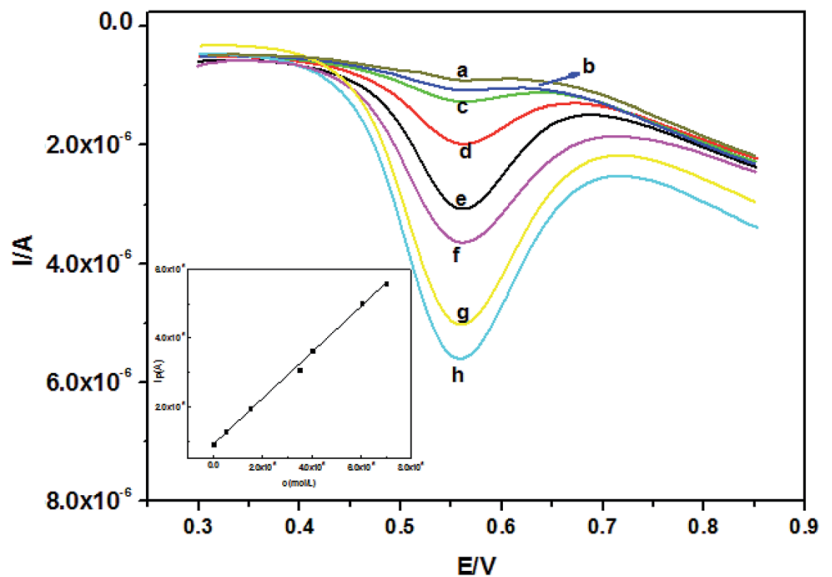

Fig. 9 DPV responses for SH- $\beta$-CD-AuNPs-1/GO/GCE for different concentrations of TBBPA. (a-h) $1.5 \times 10^{-8}, 5 \times 10^{-8}, 5 \times 10^{-7}, 1.5 \times$ $10^{-6}, 3.5 \times 10^{-6}, 4 \times 10^{-6}, 6 \times 10^{-6}$, and $7 \times 10^{-6} \mathrm{~mol} \mathrm{~L}^{-1}$, respectively. Inset: calibration curve.

The electrochemical behavior of $5 \times 10^{-7} \mathrm{~mol} \mathrm{~L}^{-1}$ TBBPA on the bare GCE (a), GO/GCE (b), AuNPs-1/GO/GCE (c), SH- $\beta$-CDAuNPs-3/GO/GCE (d), SH- $\beta$-CD-AuNPs-2/GO/GCE (e), and SH$\beta$-CD-AuNPs-1/GO/GCE (f) was studied by cyclic voltammetry in a $0.1 \mathrm{~mol} \mathrm{~L}^{-1} \mathrm{PBS}$ buffer solution ( $\mathrm{pH} 7.0$ ) at a scan rate of $50 \mathrm{mV}$ $\mathrm{s}^{-1}$. As shown in Fig. 4, only one anodic peak is present for all electrodes over the scanning range, suggesting that the electrochemical process of TBBPA involved totally irreversible electronic oxidation. Poorly defined oxidation peaks were observed at the bare GCE (a) and at the GO/GCE (b) electrodes. For AuNPs-1/GO/GCE, the oxidation peak current increased clearly compared with that for the GCE (a) and GO/GCE (b) electrodes. This phenomenon can be attributed to the AuNPs/ GO, which integrates the electrical properties and larger specific surface area of GO and AuNPs. Compared with AuNPs$1 / G O / G C E$, the well-defined oxidation peaks and signal enhancement of SH- $\beta$-CD-AuNPs/GO/GCE might be attributed to the conductivity and large specific surface area of GO, together with the enriched capability of $\mathrm{SH}-\beta-\mathrm{CD}$ of forming host-guest complexes with TBBPA. Moreover, the oxidation current significantly increased as the particle size of the AuNPs decreased. In other words, the $6.2 \mathrm{~nm}$ AuNPs were much more active in the investigated electrochemical reaction than the AuNPs of other sizes. There are two possible factors for this phenomenon. Firstly, as the particle size of the AuNPs decreased, the number of active sites increased, resulting in the<smiles>CC(C)(c1cc(Br)c(O)c(Br)c1)c1cc(Br)c(O)c(Br)c1</smiles><smiles>CC1(C)C2(C=C(Br)C(=O)C(Br)=C2)OC12C=C(Br)C(=O)C(Br)=C2</smiles>

Scheme 2 The possible oxidation reaction mechanism. 
Table 1 Comparisons of various electrochemical sensors for $\operatorname{TBBPA}^{a}$

\begin{tabular}{|c|c|c|c|c|}
\hline Sensor & $\begin{array}{l}\text { Accumulation } \\
\text { time (min) }\end{array}$ & $\begin{array}{l}\text { Linear range } \\
\left(10^{-9} \mathrm{~mol} \mathrm{~L}^{-1}\right)\end{array}$ & $\begin{array}{l}\text { Detection limit } \\
\left(10^{-9} \mathrm{~mol} \mathrm{~L}^{-1}\right)\end{array}$ & Reference \\
\hline CTAB/NG-TPA/GCE & 6.0 & $10-1000$ & 9.0 & 2 \\
\hline $\mathrm{AB} / \mathrm{GCE}$ & 4.0 & $18.4-643$ & 11.2 & 17 \\
\hline TOMA/GCE & 4.0 & $1.84-919$ & 1.05 & 18 \\
\hline $\mathrm{g}-\mathrm{C}_{3} \mathrm{~N}_{4} / \mathrm{GCE}$ & 3.0 & $20-1000$ & 5.0 & 4 \\
\hline SH- $\beta$-CD-AuNPs- $1 / G O / G C E$ & 3.0 & $15-7000$ & 1.2 & This work \\
\hline
\end{tabular}

${ }^{a}$ CTAB/NG-TPA: hexadecyl trimethyl ammonium bromide/nitrogen-doped graphene-1,3,6,8-pyrenetetrasulfonic acid; MMIP: magnetic molecularly imprinted polymers; AB: acetylene black; TOMA: trioctadecylmethylammonium bromide; g- $\mathrm{C}_{3} \mathrm{~N}_{4}$ : graphitic carbon nitride; ePDA-MIP: electropolymerized dopamine molecularly imprinted films; DODMA: dioctadecyldimethylammonium bromide; SB3-16: 3-( $N, N$ dimethylpalmitylammonio)propanesulfonate.

Table 2 Interferences of substances on the oxidation peak current of 50 nM TBBPA

\begin{tabular}{|c|c|c|}
\hline Interferences & $\begin{array}{l}\text { Concentrations } \\
(\mu \mathrm{M})\end{array}$ & $\begin{array}{l}\text { Peak current changes } \\
(\%)(n=3)\end{array}$ \\
\hline $\mathrm{Ca}^{2+}$ & 25 & 0.5 \\
\hline $\mathrm{Mg}^{2+}$ & 25 & 0.2 \\
\hline $\mathrm{Fe}^{3+}$ & 25 & -0.4 \\
\hline $\mathrm{Cl}^{-}$ & 25 & 0.9 \\
\hline $\mathrm{NO}_{3}^{-}$ & 25 & 0.8 \\
\hline $\mathrm{SO}_{4}{ }^{2-}$ & 25 & -0.7 \\
\hline Bisphenol A & 0.001 & +2.1 \\
\hline$p$-Chlorophenol & 0.001 & +2.8 \\
\hline Hydroquinone & 0.001 & -1.6 \\
\hline 4-Nitrophenol & 0.001 & +3.1 \\
\hline 3-Aminophenol & 0.001 & -2.4 \\
\hline Tetrabromobisphenol S & 0.001 & -3.9 \\
\hline
\end{tabular}

assembly of more SH- $\beta$-CD molecules, which could accumulate more TBBPA on the electrode surface by a host-guest interaction. Secondly, when the particle size of AuNPs became smaller, which had a higher surface area and conductivity, the electrocatalytic activity of the AuNPs was enhanced. Therefore, $6.2 \mathrm{~nm}$ AuNPs were chosen for the following experiments because of their higher electrocatalytic activity.

\subsection{Influence of accumulation time}

The influence of accumulation time on the oxidation peak current of $5 \times 10^{-7} \mathrm{~mol} \mathrm{~L}^{-1} \mathrm{TBBPA}(\mathrm{pH}=7)$ was investigated by differential pulse voltammetry. It was found that the oxidation

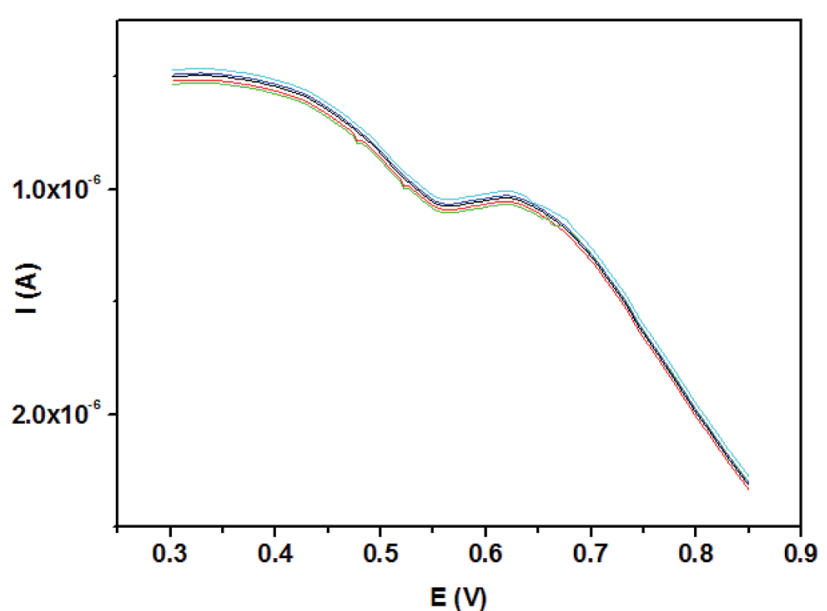

Fig. 10 The reproducibility results of the $\mathrm{SH}-\beta-\mathrm{CD}-\mathrm{AuNPs} / \mathrm{GO} / \mathrm{GCE}$ sensor for the detection of TBBPA.

peak current increased when the accumulation time was below $180 \mathrm{~s}$ (Fig. 5). However, the peak current reached a plateau as the accumulation time continued to increase. This phenomenon may be ascribed to the saturated adsorption of TBBPA at the electrode surface.

\subsection{Effect of solution $\mathbf{p H}$}

In this work, $0.1 \mathrm{~mol} \mathrm{~L}^{-1} \mathrm{PBS}$ was used to evaluate the effects of $\mathrm{pH}$ on the electrochemical properties of the sensor, with the concentration of TBBPA at $1 \times 10^{-7} \mathrm{~mol} \mathrm{~L}^{-1}$. As the $\mathrm{pH}$ of

Table 3 Determination of TBBPA in water samples

\begin{tabular}{|c|c|c|c|c|c|c|c|c|}
\hline \multirow[b]{2}{*}{ Sample } & \multirow[b]{2}{*}{ Original } & \multirow{2}{*}{$\begin{array}{l}\text { Added } \\
(\mathrm{nM})\end{array}$} & \multicolumn{3}{|c|}{ This method $(n=3)$} & \multicolumn{3}{|c|}{$\operatorname{HPLC}(n=3)$} \\
\hline & & & Found & Recovery & RSD & Found & Recovery & RSD \\
\hline 1 & 0 & 50 & 47.14 & $94.3 \%$ & 4.2 & 50.16 & $100.3 \%$ & 2.1 \\
\hline 2 & 0 & 200 & 195.6 & $97.8 \%$ & 3.2 & 198.4 & $99.2 \%$ & 1.8 \\
\hline 3 & 0 & 500 & 494.2 & $98.9 \%$ & 2.8 & 490.7 & $98.1 \%$ & 2.0 \\
\hline 4 & 0 & 1000 & 990.1 & $99.1 \%$ & 3.6 & 991.5 & $99.2 \%$ & 2.2 \\
\hline
\end{tabular}


the PBS solution increased from 5.0 to 8.5, the peak current value reached a maximum at a $\mathrm{pH}$ of 7.0, and then decreased with a further increase of $\mathrm{pH}$ (Fig. 6). A pH of 7.0 was therefore chosen as the optimal experimental condition. On the other hand, the potential of the oxidation peak shifted negatively as the $\mathrm{pH}$ of the PBS solution increased. This indicated that protons $\left(\mathrm{H}^{+}\right)$are directly involved in the electrochemical oxidation process of TBBPA. The peak potential $\left(E_{\mathrm{p}}\right)$ was linear to the $\mathrm{pH}$ value with an equation of $E_{\mathrm{p}}(\mathrm{V})=$ $-0.0557 \mathrm{pH}+0.9214(R=0.995)$ (Fig. 6). The slope value was approximately close to the theoretical value of $-0.059 \mathrm{~V}$ per $\mathrm{pH}(298 \mathrm{~K})$, indicating that the number of protons and electrons involved in the electrochemical oxidation process of TBBPA should be equal.

\subsection{Influence of scan rate}

To examine the details of the oxidation process of TBBPA, cyclic voltammograms of $1 \times 10^{-7} \mathrm{~mol} \mathrm{~L}^{-1}$ TBBPA at different scan rates from 20 to $200 \mathrm{mV} \mathrm{s}^{-1}$ were obtained in $0.1 \mathrm{M}$ phosphate buffer $(\mathrm{pH}=7.0)$. As shown in Fig. 7, the oxidation peak current enhanced linearly against the scan rate, implying an adsorption controlled process in the scan rate range. A linear relationship was obtained with the regression equation: $I_{\mathrm{P}}(\mathrm{A})=-9.26 \times$ $10^{-7}-2.731 \times 10^{-5} v\left(\mathrm{~V} \mathrm{~s}^{-1}\right), R=0.999$. Similarly, $E_{\mathrm{P}}$ had a linear relation to $\operatorname{lnv}$, with a regression equation of $E_{\mathrm{p}}(\mathrm{V})=$ $0.58+0.0159 \ln v\left(\mathrm{~V} \mathrm{~s}^{-1}\right), R=0.99$ (Fig. 8). According to the Butler-Volmer equation: $E_{\mathrm{p}}(\mathrm{V})=E_{0}-(R T / \beta n F) \ln \left(R T K_{0} / \beta n F\right)$ $+(R T / 2 \beta n F) \ln v,^{31}$ a $\beta \times n$ value of 0.8042 was calculated from the slope of linearity between $E_{\mathrm{p}}$ and $\operatorname{lnv}$. Based on the above analysis, $\beta$ (anodic transfer coefficient) can be from 0.4 to $0.6,{ }^{32}$ so $n$ and $\beta$ were equal to 2 and 0.4021 , respectively. Therefore, the electron transfer number $(n)$ was approximately 2 in the electrochemical oxidation process. Considering that the number of electrons and protons involved in the TBBPA oxidation process is equal, the electrooxidation of TBBPA on the SH- $\beta$-CD-AuNPs-1/GO/GCE electrode is a two-electron and twoproton process.

A possible oxidation reaction mechanism is shown in Scheme 2. In this mechanism, TBBPA is oxidized to quinone.

\subsection{Electrochemical determination of TBBPA}

Under the optimized conditions, the determination of TBBPA was characterized by differential pulse voltammetry (DPV). The DPV results for different concentrations $\left(1.5 \times 10^{-8}, 5 \times 10^{-8}, 5\right.$ $\times 10^{-7}, 1.5 \times 10^{-6}, 3.5 \times 10^{-6}, 4 \times 10^{-6}, 6 \times 10^{-6}$, and $7 \times$ $10^{-6} \mathrm{~mol} \mathrm{~L}^{-1}$ ) of TBBPA are shown in Fig. 9. In Fig. 9, the oxidation peak currents proportionally increased with the increase in concentration of TBBPA, with a linear regression of $I_{\mathrm{p}}(\mathrm{A})=0.673 C\left(\mathrm{~mol} \mathrm{~L}^{-1}\right)+9.01 \times 10^{-7}\left(R^{2}=0.998\right)$. The detection limit was calculated to be $1.2 \times 10^{-9} \mathrm{~mol} \mathrm{~L}^{-1}(\mathrm{~S} / \mathrm{N}=$ 3).

A comparison of the modified electrodes, accumulation times, linear ranges and detection limits with other published papers of TBBPA is displayed in Table 1 . The results indicate that this new sensing platform has a shorter accumulation time and a wider linear range, and so is competitive in determining TBBPA.

\subsection{Interferences and application in water samples}

The influence of some potential interferents, including bisphenol A, p-chlorophenol, hydroquinone, 4-nitrophenol, 3aminophenol, tetrabromobisphenol $\mathrm{S}$, and various inorganic ions was examined under optimal conditions, and the results are shown in Table 2. As shown in Table 2, a non-significant influence on the detection of $1 \times 10^{-7} \mathrm{~mol} \mathrm{~L}^{-1}$ TBBPA was observed after the addition of 500-fold amounts of varied ions such as $\mathrm{Ca}^{2+}, \mathrm{Mg}^{2+}, \mathrm{Fe}^{3+}, \mathrm{Cl}^{-}, \mathrm{NO}_{3}{ }^{-}$, and $\mathrm{SO}_{4}{ }^{2-}$. Although 2-fold amounts of bisphenol A, p-chlorophenol, hydroquinone, 4nitrophenol, 3-aminophenol, and tetrabromobisphenol $\mathrm{S}$ showed interference in the determination of TBBPA at different levels due to the presence of similar functional groups to TBBPA, the peak current changes were all less than $4 \%$. These results indicated that the $\mathrm{SH}-\beta$-CD-AuNPs/GO/GCE electrode had an acceptable selectivity for the method of detecting TBBPA.

To test its practical application, the fabricated sensor was used for the detection of TBBPA in water samples from the Guizhou Chishui river basin. As TBBPA was not detected in these water samples, the recovery of the sensor was investigated by adding known amounts of TBBPA solution in the water samples and these were used for quantitative analysis by DPV, and the results are displayed in Table 3. The percentage recoveries of the sensor were from $94.3 \%$ to $99.1 \%$. To investigate the accuracy of this sensor, the results of the electrochemical method were compared with those from the HPLC method. As shown in Table 3, the results obtained from the SH- $\beta$-CDAuNPs/GO/GCE sensor exhibited good agreement with the HPLC values. The real sample measurements indicated that the proposed sensor can be successfully applied in the detection of TBBPA in real water samples.

\subsection{Reproducibility and stability}

The reproducibility of the SH- $\beta$-CD-AuNPs/GO/GCE electrode was evaluated to test the precision and practicability of the proposed method by the detection of $5 \times 10^{-8} \mathrm{~mol} \mathrm{~L}^{-1} \mathrm{TBBPA}$ for five successive measurements. The relative standard deviation (RSD) was calculated to be $2.09 \%$ among these five measurements in the same sensor (Fig. 10), revealing that the SH- $\beta$-CD-AuNPs/GO/GCE sensor had good fabrication reproducibility and good detection precision. Prior to obtaining the corresponding measurements, the modified electrode was kept at $4{ }^{\circ} \mathrm{C}$ in a refrigerator for 14 days. The modified electrode maintained $92.3 \%$ of its initial current response, indicating the reliable stability of this sensor.

\section{Conclusions}

In summary, a SH- $\beta$-CD-AuNPs/GO/GCE sensor was fabricated for the electrochemical detection of TBBPA. EIS and CV characterization studies suggested that the size of the AuNPs played an important role in the electrochemical performance of 
quantifying the concentration of TBBPA. The results demonstrated that the $6.2 \mathrm{~nm}$ (set A) CTAB-stabilized AuNPs were much more active for the electrochemical detection of TBBPA than the AuNPs with a diameter of 10.1 or $16.1 \mathrm{~nm}$ (sets B and C, respectively). This may be attributed to the fact that the AuNPs with a smaller size could effectively accelerate the electron transfer and enrich more $\mathrm{SH}-\beta-\mathrm{CD}$ than the larger ones. In addition, the influence of $\mathrm{pH}$ of the buffer solution, and the accumulation time on the determination were both optimized. Finally, the modified electrode showed good performance in detecting TBBPA in water samples and the results showed a good agreement with those of the HPLC method.

\section{Conflicts of interest}

The authors declare no conflicts of interest.

\section{Acknowledgements}

We are very grateful to the anonymous reviewers and to the editor for the instructive comments, which are invaluable for quality improvement of the paper. This work was supported by the Special Key Laboratory of Electrochemistry for Materials of Guizhou Province (No. QJHKYZ[2018]004), the Training Project of Zunyi Municipal Innovative Talents Team (No. ZSKH[2015] 39), the Natural Science Foundation of China (No. 51561033), the Science Foundation of the Science and Technology Department of Guizhou Province (No. [2013]3110, [2014]17, [2017]7067 and [2017]7090), and the Natural Science Research Project of the Education Department of Guizhou Province (No. [2015]386 and [2016]100).

\section{References}

1 T. Debenest, F. Gagné, A. N. Petit, C. André, M. Kohli and C. Blaise, Comp. Biochem. Physiol., Part C: Toxicol. Pharmacol., 2010, 152(4), 407-412.

2 Q. Zhao, K. Zhang, G. Yu, W. Wu, X. Wei and Q. Lu, Talanta, 2016, 151, 209-216.

3 H. G. Ni and H. Zeng, Sci. Total Environ., 2013, 458-460, 1519.

4 Q. Zhao, W. Wu, X. Wei, S. Jiang, T. Zhou and Q. Li, Sens. Actuators, B, 2017, 248, 673-681.

5 S. Morris, C. R. Allchin, B. N. Zegers, J. J. H. Haftka, J. P. Boon, C. Belpaire, P. G. Leonards van Leeuwen and J. de Boer, Environ. Sci. Technol., 2004, 38, 5497-5504.

6 S. Yang, S. Wang, H. Liu and Z. Yan, Environ. Sci. Pollut. Res., 2012, 19, 4090-4096.

7 Z.-X. Shi, Y.-N. Wu, J.-G. Li, Y.-F. Zhao and J.-F. Feng, Environ. Sci. Technol., 2009, 43, 4314-4319.

8 R. Guyot, F. Chatonnet, B. Gillet, S. Hughes and F. Flamant, Toxicology, 2014, 325, 125-132.
9 J. Yang and K. M. Chan, Aquat. Toxicol., 2015, 159, 138-147. 10 W. Watanabe, T. Shimizu, R. Sawamura, A. Hino, K. Konno, A. Hirose and M. Kurokawa, Int. Immunopharmacol., 2010, 10, 393-397.

11 H. S. Hendriks, R. G. D. M. van Kleef, M. van den Berg and R. H. S. Westerink, Toxicol. Sci., 2012, 128, 235-246.

12 J. Tollbäck, C. Crescenzi and E. Dyremark, J. Chromatogr. A, 2006, 1104, 106-112.

13 R.-S. Zhao, S.-S. Wang, C.-G. Cheng, L.-L. Zhang and X. Wang, Chromatographia, 2011, 73, 793-797.

14 S. Jian, G. Tian, J. Yunshan, W. Juan and W. Kangbing, J. Electroanal. Chem., 2018, 10-15.

15 W. Xiaoyun, Z. Qiang, W. Weixiang, Z. Tong, J. Shunli and T. Yeqing, Sensors, 2016, 16(9), 1539.

16 T. Zhou, Y. Feng, L. Zhou, Y. Tao, D. Luo, T. Jing, X. Shen, Y. Zhou and S. Mei, Sens. Actuators B Chem., 2016, 236, 153-162.

17 X. Chen, M. Zheng, Y. Zhou, J. Tong and K. Wu, RSC Adv., 2015, 5(128), 105837-105843.

18 X. Chen, L. Ji, Y. Zhou, S. Xia, J. Tong and K. Wu, Electrochim. Acta, 2016, 190, 490-494.

19 W. Xiaoyun, Z. Qiang, W. Weixiang, Z. Tong, J. Shunli and T. Yeqing, Sensors, 2016, 6(9), 1539.

20 E. Mazzotta, C. Malitesta and E. Margapoti, Anal. Bioanal. Chem., 2013, 405, 3587-3592.

21 H. Wang, S. Zhang, S. Li and J. Qu, Talanta, 2018, 188-194.

22 Y. M. Kamil, M. H. A. Bakar, A. S. A. Hamzah, M. H. Yaacob, L. H. Ngee and M. A. Mahdi, IEEE J. Sel. Top. Quantum Electron., 2018, DOI: 10.1109/jstqe.2018.2846044.

23 D. Xiaoyang, Z. Xiaoxia, J. Chunlai, Z. Weilu and Y. Lizhu, Sensors, 2018, 18(3), 681.

24 M. Jose, M. Riba-Moliner, L. J. Brennan, Y. K. Guńko, F. Céspedes, A. González-Campo and M. Baeza, Microchim. Acta, 2016, 183(5), 1579-1589.

25 Y. Fang, S. Guo, C. Zhu, Y. Zhai and E. Wang, Langmuir, 2010, 26(13), 11277-11282.

26 J. W. Park and J. S. Shumakerparry, J. Am. Chem. Soc., 2014, 136(5), 1907-1921.

27 L. L. Fang, P. Wang, X. L. Wen, X. Guo, L. D. Luo and J. Yu, Talanta, 2017, 167, 158-165.

28 T. Wu, Z. Liu, Y. Guo and C. Dong, J. Electroanal. Chem., 2015, 759, 137-143.

29 B. Nikoobakht and M. A. El-Sayed, Langmuir, 2001, 17(20), 6368-6374.

30 R. Fenger, E. Fertitta, H. Kirmse, A. F. Thünemann and K. Rademann, Phys. Chem. Chem. Phys., 2012, 14(26), 9343.

31 W. Xiang, J. Y. Li and Z. Y. Ma, Chem. Res. Appl., 2007, 19, 710-713.

32 A. J. Bard and L. R. Faulkner, Electrochemical Methods: Fundamentals and Applications, Chem. Ind. Press, Beijing, 2005. 